\title{
DNER promotes epithelial-mesenchymal transition and prevents chemosensitivity through the Wnt/ $\beta$-catenin pathway in breast cancer
}

\author{
Zhong Wang ${ }^{1}$, Zhiyu Li', Qi Wu', Chenyuan $\mathrm{Li}^{1}$, Juanjuan $\mathrm{Li}^{1}$, Yimin Zhang ${ }^{1}$, Changhua Wang ${ }^{2}$, Si Sun ${ }^{3}$ and \\ Shengrong Sun'
}

\begin{abstract}
Breast cancer (BC) is the most common malignant tumour in women worldwide, and one of the most common fatal tumours in women. Delta/Notch-like epidermal growth factor (EGF)-related receptor (DNER) is a transmembrane protein involved in the development of tumours. The role and potential mechanism of DNER in epithelial-mesenchymal transition (EMT) and apoptosis in BC are not fully understood. We find that DNER is overexpressed in $B C$ tissue, especially triple-negative breast cancer (TNBC) tissue, and related to the survival of $B C$ and TNBC patients. In addition, DNER regulates cell EMT to enhance the proliferation and metastasis of BC cells via the $W n t / \beta$-catenin pathway in vitro and in vivo. Moreover, the expression levels of $\beta$-catenin and DNER in BD tissue are positively correlated. The simultaneously high expression of DNER and $\beta$-catenin contributes to poor prognosis in BC patients. Finally, DNER protects BC cells from epirubicin-induced growth inhibition and apoptosis via the Wnt/ $\beta$-catenin pathway. In conclusion, these results suggest that DNER induces EMT and prevents apoptosis by the Wnt/ $\beta$-catenin pathway, ultimately promoting the malignant progression of BC. In conclusion, our study demonstrates that DNER functions as an oncogene and potentially valuable therapeutic target for BC.
\end{abstract}

\section{Introduction}

Breast cancer $(\mathrm{BC})$ is the most common malignant tumour in women worldwide and one of the most common fatal tumours in women ${ }^{1,2}$. BC treatments can be used to improve patient outcome ${ }^{3}$. However, tumour recurrence and metastasis and chemotherapeutic resistance are the most common causes of cancer treatment failure. Therefore, the need to screen and identify key regulatory factors in the process of tumour recurrence and metastasis for the treatment of $\mathrm{BC}$ is urgent.

\footnotetext{
Correspondence: Si Sun (karensisi@126.com) or Shengrong Sun (sun137@sina. com)

'Department of Breast and Thyroid Surgery, Renmin Hospital of Wuhan University, Wuhan, Hubei, China

${ }^{2}$ Department of Pathophysiology, Wuhan University School of Basic Medical Sciences, Wuhan, Hubei, China

Full list of author information is available at the end of the article

These authors contributed equally: Zhong Wang, Zhiyu Li

Edited by S Tait
}

Tumour EMT is a multifactorial and complex event in which epithelial properties and the ability to adhere to adjacent cells are lost and mesenchymal and stem cell phenotypes are eventually obtained ${ }^{4-7}$. EMT, a crucial regulatory mechanism by which tumours acquire invasive and metastatic abilities and the ability to resist apoptosis, plays an irreplaceable role in the development of malignant tumours ${ }^{8-10}$. Recent studies upon activation of the classical Wnt $/ \beta$-catenin pathway, $\beta$-catenin enters and accumulates in the nucleus, which induces the transcription and translation of downstream target genes, thus accelerating $\mathrm{EMT}^{10}$. Therefore, maintaining $\beta$-catenin activity is important for the $\mathrm{Wnt} / \beta$-catenin pathway and tumour progression.

DNER, a neuron-specific transmembrane protein found in a variety of peripheral cells ${ }^{11-14}$, is a member of the atypical Notch ligand family and binds to Notch1 recep$\operatorname{tor}^{11,15}$. DNER is expressed at abnormally high levels in

\section{(c) The Author(s) 2020}

(c) (i) Open Access This article is licensed under a Creative Commons Attribution 4.0 International License, which permits use, sharing, adaptation, distribution and reproduction c. in any medium or format, as long as you give appropriate credit to the original author(s) and the source, provide a link to the Creative Commons license, and indicate if changes were made. The images or other third party material in this article are included in the article's Creative Commons license, unless indicated otherwise in a credit line to the material. If material is not included in the article's Creative Commons license and your intended use is not permitted by statutory regulation or exceeds the permitted use, you will need to obtain permission directly from the copyright holder. To view a copy of this license, visit http://creativecommons.org/licenses/by/4.0/. 
various cancer tissues ${ }^{16}$ and promotes the proliferation migration, and invasion of cancer cells ${ }^{16,17}$ but has an inhibitory effect on cell proliferation in glioma ${ }^{14}$. Nevertheless, the precise function and underlying molecular mechanisms of EMT and chemosensitivity in BC are unclear.

In this study, we have revealed the previously unrecognized role of DNER in cancer progression, EMT and the apoptosis of $\mathrm{BC}$ cells. Furthermore, we investigated the expression of DNER and its relationship with survival in $\mathrm{BC}$ and TNBC patients. In addition, we have provided evidence for the correlation between DNER and $\beta$-catenin and the prognostic value of the high-level expression of DNER and catenin in BC patients. Finally, the crucial role of $\beta$-catenin in DNER-induced EMT and the inhibitory effect of DNER on apoptosis have been revealed. Taken together, our results elucidate the potential functions and mechanism of DNER in EMT and apoptosis in BC cells and provide a new therapeutic pathway for the recurrence, metastasis and chemotherapy resistance of $\mathrm{BC}$.

\section{Materials and methods}

\section{Ethics statement}

Two groups of the same human tissue specimens were acquired from patients of Renmin Hospital of Wuhan University who were diagnosed with BC from 2010 to 2012. One group of specimens was promptly stored at $-80^{\circ} \mathrm{C}$ for western blotting and PCR analysis. The other group of specimens was fixed in formalin and paraffinized for immunohistochemistry (IHC). All patients did not receive chemotherapy, radiotherapy or immunotherapy. This research was approved by the Ethics Committee of Renmin Hospital of Wuhan University, and informed consent was obtained from all patients.

\section{Cell culture and reagents}

Human BC cell lines (MCF-7 and MDA-MB-468 cells) were obtained from American Type Culture Collection and incubated by their corresponding recommended method. All cell lines were mycoplasma-free by morphological examination and verified for their authenticities by STR profiling. Epirubicin was purchased from Pfizer Pharmaceutical Co., Ltd. (Wuxi, China) and dissolved in physiological saline. CHIR 99021 ( $\beta$-catenin inhibitor) and XAV-939 ( $\beta$-catenin agonist) were purchased from Selleck (Shanghai, China) and dissolved in DMSO.

\section{Immunohistochemical staining}

IHC staining was performed as previously described ${ }^{18}$. The results of IHC staining were evaluated by two independent pathologists and scored according to the percentage of positive tumour cells and staining intensity. The percentage of positive cells was scored as follows: $0<$
$10 \%, 1=10-20 \%, 2=21-50 \%$ and $3>50 \%$. The staining intensity was evaluated as follows: $0=$ no staining, $1=$ weak staining, $2=$;moderate staining and $3=$;strong staining. The final protein staining score was the percentage score multiplied by the intensity score; final protein staining scores were divided into three categories as follows: $0=$ negative, $1-3=$ low expression and $4-9=$ high expression.

\section{siRNA and plasmid transfection}

DNER siRNA (5'-GCUUUGCCAGUCCAAGAUUTT) and scramble siRNA (5'-UUCUCCGAACGUGUCACGUTT) were synthesized from GenePharma Co. (Shanghai, China). FLAG-DNER and FLAG-NC were purchased from GeneChem Co. (Shanghai, China). When cells in a six-well plate had grown to the appropriate density, siRNA and plasmids were transiently transfected with Lipofectamine3000 (Invitrogen, USA) and RNAiMAX (Invitrogen, USA), respectively, according to the manufacturer's instructions. After $48 \mathrm{~h}$ of transfection, the cells were used for subsequent experiments.

\section{qRT-PCR}

Total RNA from tissue specimens and cell samples was extracted by using TRIzol (Invitrogen, USA) according to the protocol and then reverse transcribed to cDNA using a TransScript First-Stand cDNA Synthesis Kit (TaKaRa, Japan). qRT-PCR was implemented by using SYBR Green Mastermix (TaKaRa, Japan) with an ABI 7900HT RealTime PCR system (USA). The primer sequences are shown in Supplemental Table 1.

\section{Cell Counting Kit (CCK)-8 assay}

After a series of interventions, equal numbers of $\mathrm{BC}$ cells were plated into 96-well plates and cultured for 4 days. Ten microlitres of CCK-8 (CK04, Dojindo, Japan) solution was added to each well, and the cells were incubated at $37^{\circ} \mathrm{C}$ for $2 \mathrm{~h}$. The absorbance was determined at $450 \mathrm{~nm}$.

\section{Wound healing assay}

After intervention, the cells were seeded into six-well plates. When the cell density exceeded $90 \%$, the cells were washed twice with PBS, and scratches were made with a yellow plastic pipette tip. Cells were cultured in serumfree medium for $48 \mathrm{~h}$ and photographed under a microscope.

\section{Invasion assay}

After a series of treatments, $4 \times 10^{4}$ cells in serum-free medium were plated in the upper chambers of a Transwell apparatus with Matrigel (Corning, NY, USA). Medium in the bottom chambers containing 10\% FBS served as an attractant. After $24 \mathrm{~h}$ of incubation, cells that passed 
through the chamber membrane were fixed with precooled formaldehyde and stained with crystal violet (C0121, Beyotime). The cells were counted and photographed under a microscope.

\section{Western blotting}

The prepared tissue and cell samples were separated by protein SDS-PAGE and transferred to a nitrocellulose (NC) membrane. The membrane was blocked in 5\% skim milk powder for $1.5 \mathrm{~h}$ at room temperature and immunoblotted with primary antibody at $4{ }^{\circ} \mathrm{C}$ overnight. After incubation with secondary antibody at room temperature for $1 \mathrm{~h}$, protein expression was detected with corresponding protein development instrument and quantified by Image software (W S Rasband, Image J, NIH). The antibodies used are listed in Supplementary Table 2.

\section{Nuclear and cytoplasmic protein extraction}

Nuclear and Cytoplasmic Extraction Reagent (P0027) was purchased Beyotime Biotechnology. The nuclear and cytoplasmic proteins were extracted according to the instructions and then used for subsequent experiments.

\section{Flow cytometry to detect apoptosis}

A FITC Annexin V Apoptosis Detection Kit I (556547, BD Pharmingen, USA) was used to detect cell apoptosis. The cells were seeded in six-well plates. After a series of interventions, cells were processed following the manufacturer's protocol,

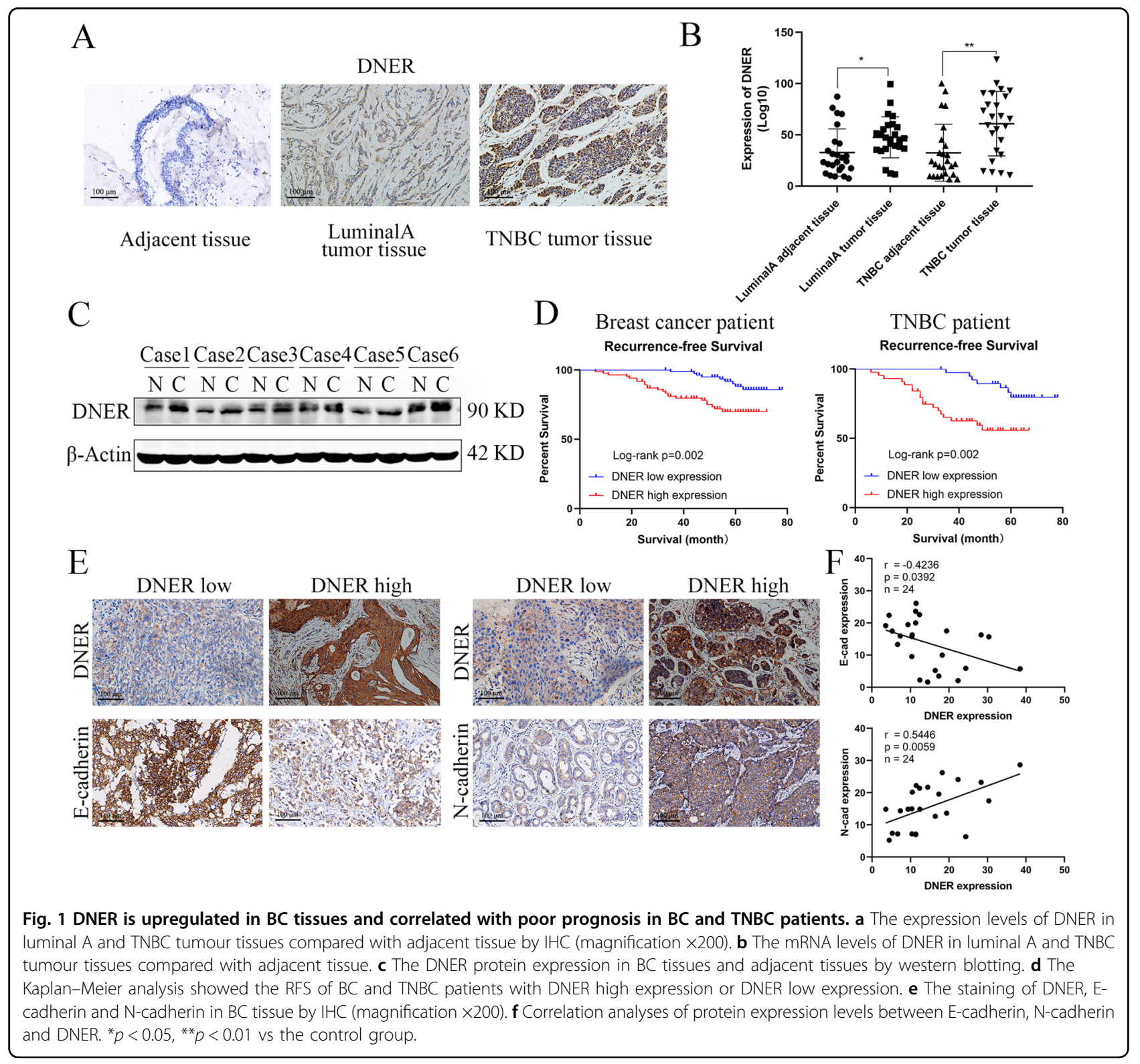


and the cell fluorescence was measured with a FACScan flow cytometer (FACScan, Becton Dickinson).

\section{Animal experiments}

To acquire MDA-MB-468 cells with DNER stably knocked down and MCF-7 cells stably overexpressing DNER, cells were transfected with DNER knockdown and overexpression lentivirus (GeneChem, Shanghai, China) and then selected with puromycin. When the transfection efficiency approached $\sim 90 \%$, the DNER protein level was detected with western blotting. All experimental procedures were conducted according to the Regulations of Experimental Animal Administration issued by the Animal Committee of Wuhan University. The mice were randomly divided into two groups. A total of $4 \times 10^{6}$ stable cells in $250 \mu \mathrm{l}$ PBS were subcutaneously inoculated into the right iliac fossa of 4- to 5-week-old female athymic nude mice $(B A L B / c)$. After a certain period of intervention, the mice were sacrificed by anaesthesia, and xenografts were removed for weighing and photographing. The expression of relative proteins was detected by western blotting and IHC.

For mammary-fat-pad tumour assays, we established MDA-MB-231 cells with DNER stably knocked down. The mice were randomly divided into two groups. $1.5 \times$ $10^{6}$ stable cells were resuspended in a mixture of PBS and Matrigel (1:1) and then injected into the fourth mammary fat pad on the same side of nude mice. To observe lung metastasis, tumours were excised by surgical operation when they reached about $300 \mathrm{~mm}^{3}$. Ten days after the operation, the mice were sacrificed by anaesthesia, and the number of metastatic tumours per lung were determined. The entire lung tissues were fixed with $10 \%$ formalin and sectioned for haematoxylin and eosin (H\&E) staining to determine the presence of lung metastasis. The entire lung tissues were fixed with $10 \%$ formalin and sectioned for haematoxylin and eosin (H\&E) staining to determine the presence of lung metastasis.

\section{Immunofluorescence}

Immunofluorescence staining was performed as previously described ${ }^{19}$. In brief, after corresponding treatments, the cells fixed with $4 \%$ paraformaldehyde were perforated by $0.2 \%$ Triton-X 100 for $15 \mathrm{~min}$ and blocked with $5 \%$ BSA for $1 \mathrm{~h}$. Next, the cells were incubated with $\beta$-catenin (1:100 dilution) overnight at $4{ }^{\circ} \mathrm{C}$ and then incubated for $30 \mathrm{~min}$ with 488-conjugated antibody (Invitrogen, A11034). Finally, the slides were stained with DAPI for $3 \mathrm{~min}$. The images of sample were analyzed by laser confocal microscopy (Zeiss LSM 710).

\section{Statistical analysis}

Statistical analyses were performed using SPSS 24.0 software (SPSS Inc., Chicago, IL) and GraphPad
Table 1 Clinicopathological associations of DNER expression in breast cancer.

\begin{tabular}{|c|c|c|c|}
\hline Variables & $\begin{array}{l}\text { Low } \\
N=92(\%)\end{array}$ & $\begin{array}{l}\text { High } \\
N=114 \text { (\%) }\end{array}$ & $P$ value ${ }^{*}$ \\
\hline Age at diagnosis, years & & & 0.664 \\
\hline$\leq 50$ & $21(22.8)$ & $29(25.4)$ & \\
\hline$>50$ & $71(77.2)$ & $85(74.6)$ & \\
\hline Grade & & & 0.043 \\
\hline Well & $17(18.5)$ & $9(7.9)$ & \\
\hline Moderately & $24(26.1)$ & $26(22.8)$ & \\
\hline Poorly & $51(55.4)$ & $79(69.3)$ & \\
\hline Tumour size $(\mathrm{cm})$ & & & 0.073 \\
\hline$\leq 2$ & $47(51.1)$ & $44(38.6)$ & \\
\hline$>2$ & $45(48.9)$ & $70(61.4)$ & \\
\hline Lymph node metastasis & & & 0.759 \\
\hline Negative & $35(38.0)$ & $41(36.0)$ & \\
\hline Positive & $57(62.0)$ & $73(64.0)$ & \\
\hline Vascular invasion & & & 0.098 \\
\hline Negative & $78(84.8)$ & $86(75.4)$ & \\
\hline Positive & $14(15.2)$ & $28(24.6)$ & \\
\hline ER & & & 0.152 \\
\hline Negative & $69(75.0)$ & $75(65.8)$ & \\
\hline Positive & $23(25.0)$ & $39(34.2)$ & \\
\hline PR & & & 0.034 \\
\hline Negative & $55(59.8)$ & $84(73.7)$ & \\
\hline Positive & $37(40.2)$ & $30(26.3)$ & \\
\hline HER2 & & & 0.381 \\
\hline Negative & $58(63.0)$ & $65(57.0)$ & \\
\hline Positive & $34(37.0)$ & $49(43.0)$ & \\
\hline Ki67 & & & 0.535 \\
\hline$<14 \%$ & $72(78.3)$ & $85(74.6)$ & \\
\hline$\geq 14 \%$ & $20(21.7)$ & $29(25.4)$ & \\
\hline Recurrence & & & 0.041 \\
\hline No & 83(90.2) & $91(79.8)$ & \\
\hline Yes & $9(9.8)$ & $23(20.2)$ & \\
\hline
\end{tabular}

${ }^{*} P$ values calculated by log-rank testing; bold if statistically significant, $P<0.05$ $E R$ oestrogen receptor, $P R$ progesterone receptor, $H E R 2$ human epithelial growth factor receptor-2.

Prism 8 (GraphPad Software, La Jolla, CA, USA). All data were analyzed with at least three independent experiments and are presented as the mean \pm SD. A survival curve was prepared by Kaplan-Meier analysis, and the log-rank test was used to compare survival differences between groups. Pearson's correlation method was used 
Table 2 Clinicopathological associations of DNER expression in triple negative breast cancer.

\begin{tabular}{|c|c|c|c|}
\hline Variables & $\begin{array}{l}\text { Low } \\
N=47 \text { (\%) }\end{array}$ & $\begin{array}{l}\text { High } \\
N=51 \text { (\%) }\end{array}$ & $P$ value ${ }^{*}$ \\
\hline Age at diagnosis, years & & & 0.818 \\
\hline$\leq 50$ & $12(25.5)$ & $12(23.5)$ & \\
\hline$>50$ & $35(74.5)$ & $39(76.5)$ & \\
\hline Grade & & & 0.037 \\
\hline Well & $6(12.8)$ & $2(3.9)$ & \\
\hline Moderately & $12(25.5)$ & $6(11.8)$ & \\
\hline Poorly & $29(61.7)$ & $43(84.3)$ & \\
\hline Tumour size $(\mathrm{cm})$ & & & 0.048 \\
\hline$\leq 2$ & $23(48.9)$ & $15(29.4)$ & \\
\hline$>2$ & $24(51.1)$ & $36(70.6)$ & \\
\hline Lymph node metastasis & & & 0.113 \\
\hline Negative & $25(53.2)$ & $19(37.3)$ & \\
\hline Positive & $22(46.8)$ & $32(62.7)$ & \\
\hline Vascular invasion & & & 0.398 \\
\hline Negative & $35(74.5)$ & $33(64.7)$ & \\
\hline Positive & $12(25.5)$ & $18(35.3)$ & \\
\hline Ki67 & & & 0.481 \\
\hline$<14 \%$ & $30(63.8)$ & $29(56.9)$ & \\
\hline$\geq 14 \%$ & 17 (36.2) & $22(43.1)$ & \\
\hline Recurrence & & & 0.021 \\
\hline No & $40(85.1)$ & $33(64.7)$ & \\
\hline Yes & $7(14.9)$ & $18(35.3)$ & \\
\hline
\end{tabular}

${ }^{*} P$ values calculated by log-rank testing; bold if statistically significant, $P<0.05$.

to analyze the correlation between DNER and $\beta$-catenin. A chi-square test was used to analyze associations between DNER expression levels and clinical characteristics. One-way ANOVA was used to compare differences in three or more groups. Differences in which $p<0.05$ were considered statistically significant.

\section{Results}

DNER is upregulated in BC tissues and correlated with poor prognosis in BC and TNBC patients

To determine the role of DNER in development of $\mathrm{BC}$, we first measured the expression levels of DNER in BC tissue and matched adjacent normal breast tissue by IHC. The expression level of DNER in BC tissue was markedly higher than that in adjacent tissue; moreover, the expression in TNBC was higher than that in luminal A BC (Fig. 1a). We also detected the expression of DNER in BC tissue by PCR, the results of which were consistent with those of IHC experiments (Fig. 1b). To further verify
DNER expression in $\mathrm{BC}$, we utilized western blotting to detect DNER protein expression in $\mathrm{BC}$ and adjacent tissues. As expected, compared with DNER expression in adjacent tissues, DNER expression in BC tissues was significantly elevated (Fig. 1c). Furthermore, the highest DNER expression level was found in TNBC tissue. The clinicopathological characteristics with different expression of DNER in all BC and TNBC patients were shown in Tables 1 and 2. Kaplan-Meier analysis of RFS showed that the group expressing high levels of DNER had a worse prognosis than the group expressing low levels of DNER. The results of survival analysis of TNBC patients were the same as that of $B C$ patients, and TNBC patients had a shorter RFS than BC patients (Fig. 1d). Next, to verify whether the poor prognosis of $\mathrm{BC}$ patients caused by DNER is related to EMT, we detected the correlation between DNER- and EMT-related markers. The results showed that DNER expression was negatively correlated with the expression of E-cadherin, while positively correlated with $\mathrm{N}$-cadherin expression (Fig. 1e, f). In addition, we found that high expression of mesenchymal markers was significantly associated with high expression of DNER in BC through the TCGA database (http://gepia. cancer-pku.cn/). Although the negative correlation between E-cadherin and DNER in TCGA database was not significant, it also presented a negative trend (Supplementary Fig. 2A). The results therefore suggested that DNER is highly expressed in $B C$ and that elevated DNER protein expression contributes to the progression of $\mathrm{BC}$, especially TNBC.

DNER increases the biological functions of $\mathrm{BC}$ cells in vitro

To evaluate the effect of DNER on BC cell proliferation, migration and invasion, we used siRNA to suppress DNER expression in both MCF-7 and MDA-MB-468 cells. Compared with DNER expression in the control and scramble siRNA groups, DNER was silenced by almost $90 \%$ and $83 \%$ in MCF-7 and MDA-MB-468 cells transfected with siRNA, respectively, (Fig. 2a, b). As shown in Fig. 2c, DNER knockdown visibly downregulated the growth rate of $\mathrm{BC}$ cells by CCK- 8 assay. Next, a wound healing assay was used to evaluate cell migration capacity. Compared with wound closure in the scramble siRNA group, DNER knockdown significantly inhibited wound closure after $48 \mathrm{~h}$ in BC cells (Fig. $2 \mathrm{~d}$ ). In addition, the Transwell assay revealed that DNER knockdown clearly reduced $B C$ cell invasion (Fig. 2e). These results suggest that DNER acts as a cancer-promoting gene in $\mathrm{BC}$ cells.

To further confirm the role of DNER in BC progression, DNER was overexpressed by transfection with the FLAGDNER plasmid for $48 \mathrm{~h}$. As shown in Supplementary Fig. 1A, DNER was successfully overexpressed in the two BC cell lines. In striking contrast with the effects of DNER knockdown, the ability of cell proliferation, migration and 
A

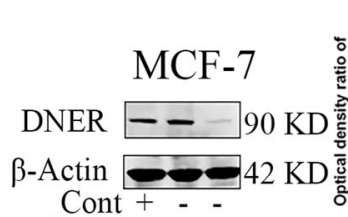

Scr SiRNA - + DNER SiRNA - - +

C

MCF-7

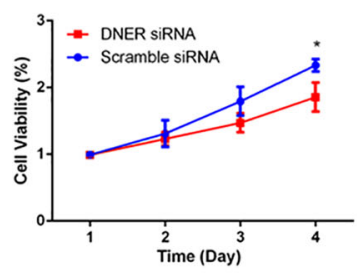

$\mathrm{E}$

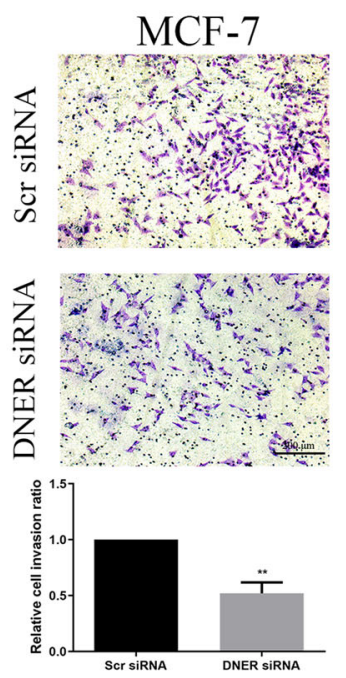

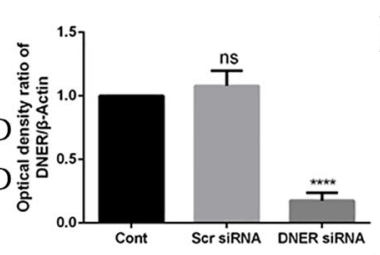

Cont Scr siRNA DNER siRNA

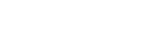

B

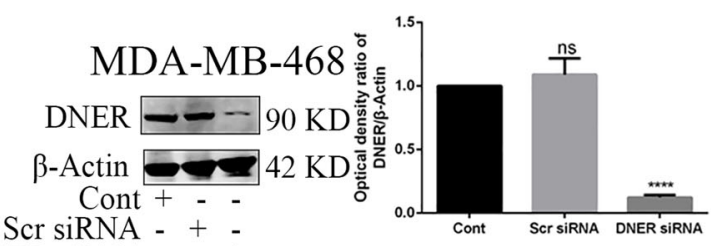

DNER SiRNA - - +

D

\section{MCF-7}
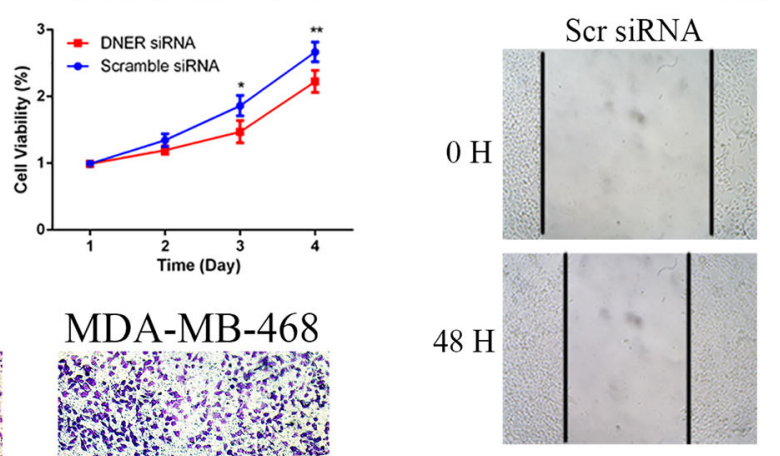

\section{DNER siRNA}
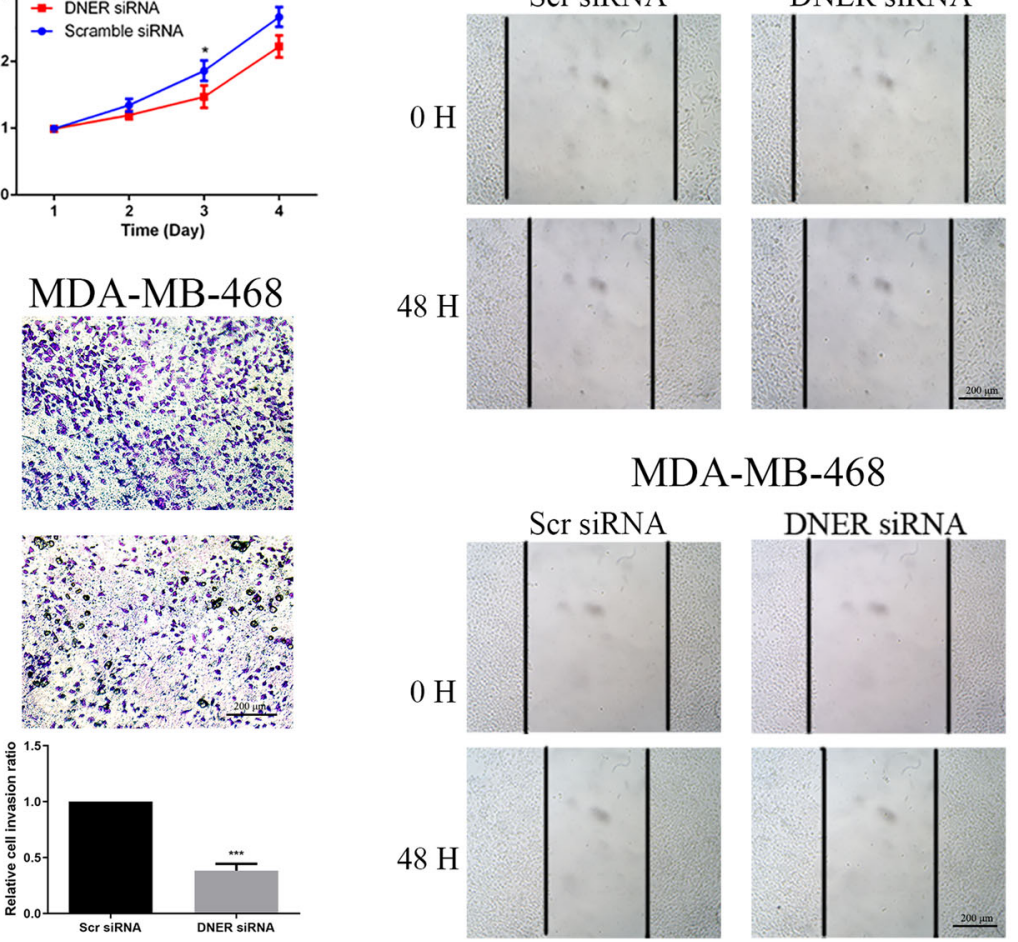

Fig. 2 DNER knockdown inhibits cell proliferation and metastasis of BC cells. $\mathbf{a}$, $\mathbf{b}$ The knockdown efficiency of DNER in MCF-7 and MDA-MB468 cells. c Cell growth was measured by CCK-8 assay after DNER knockdown in two BC cell lines. $\mathbf{d}$ Wound healing assay was used to determine the migratory ability of BC cells with DNER knockdown. e The invasion capacity of BC cells with knockdown of DNER was confirmed by Transwell assay. Down: Quantitative analysis of invasion ratio was shown. The values are the mean \pm SD from three independent experiments. ${ }^{n s} p>0.05,{ }^{*} p<0.05$, ${ }^{* *} p<0.01,{ }^{* *} p<0.001,{ }^{* * *} p<0.0001$ vs the control group.

invasion was markedly enhanced after DNER overexpression (Supplementary Fig. 1B-E). Taken together, these results indicated that DNER plays a crucial role in $\mathrm{BC}$ growth and metastatic potential.

\section{DNER induces EMT in BC cells}

Tumour cell EMT promotes the malignant progression and metastasis of tumour cells ${ }^{10}$. We next examined whether DNER has a regulatory effect on BC cell EMT. To assess this function, we detected EMT-related protein expression by western blotting. DNER knockdown significantly upregulated epithelial-like marker (E-cadherin) expression and downregulated mesenchymal marker (Ncadherin, Vimentin, Snail) expression (Fig. 3a, b). Conversely, overexpression of DNER dramatically shown the opposite effect (Fig. 3c, d). These results indicate that DNER drives EMT in BC cells. To provide further evidence of this effect of DNER on EMT, we suppressed DNER expression and then transfected cells with the FLAG-DNER plasmid to restore the DNER protein level; we then determined whether DNER overexpression could reverse changes in the expression of EMT-related proteins. As shown in Fig. 3e, f, DNER knockdown alone had an inhibitory effect on EMT, whereas DNER knockdown and FLAG-DNER transfection suppressed the effect of DNER knockdown on E-cadherin and partially restored the expression of N-cadherin, Vimentin and Snail. These results suggest that DNER plays a pivotal role in inducing EMT in BC cells. 
A

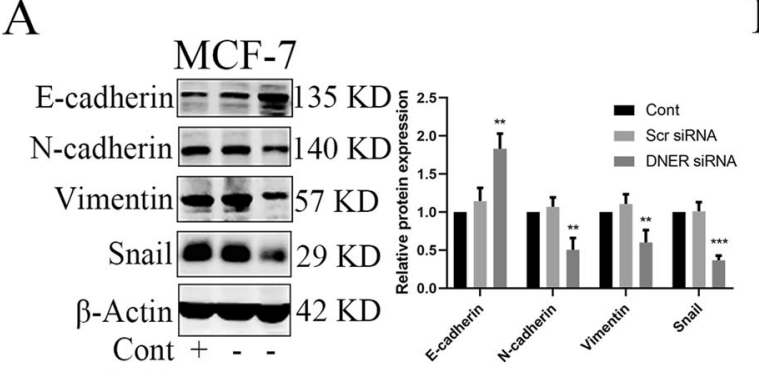

Scr siRNA - + -

DNER SIRNA - - +

C

MCF-7

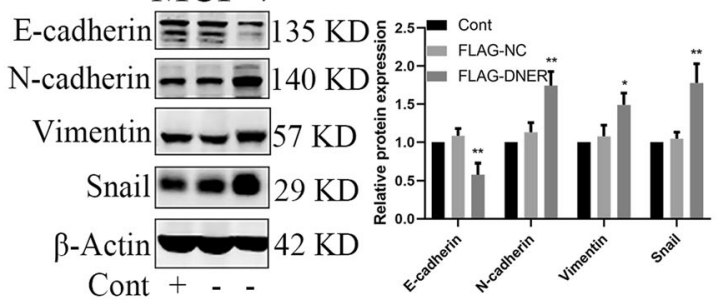

FLAG-NC - + -

FLAG-DNER - - +

E

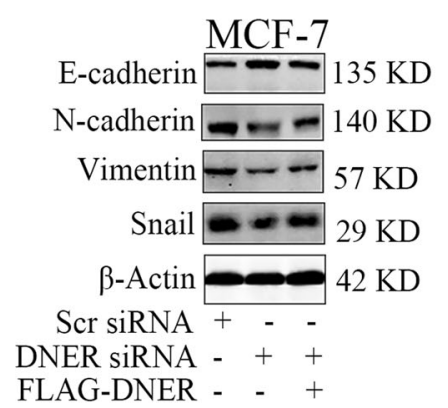

B

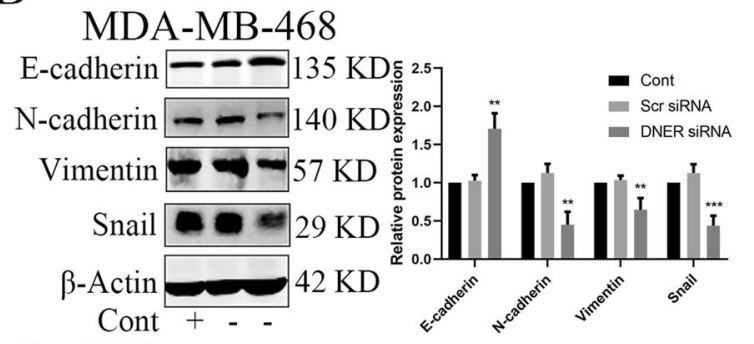

Scr SiRNA - + -

DNER SiRNA - - +

D

MDA-MB-468

E-cadherin $-0-135 \mathrm{KD}^{2.5}{ }^{2.5}{ }^{\text {cont }}$

N-cadherin $\longrightarrow \longrightarrow$ 140 KD离 $2.0-$ FLAG-NC

Vimentin --57 KD

Snail $29 \mathrm{KD}$

$\beta$-Actin $42 \mathrm{KD}$

Cont + - -

FLAG-NC - + -

FLAG-DNER - - +

$\mathrm{F}$

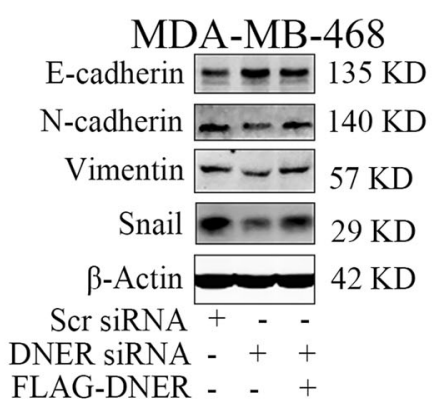

Fig. 3 DNER induces EMT in BC cells. a, b EMT-related proteins E-cadherin, N-cadherin, Vimentin, and Snail were detected by western blotting in DNER knockdown cells. Right: quantitative analysis of the optical density ratio of E-cadherin, N-cadherin, Vimentin and Snail compared with $\beta$-actin are shown. $\mathbf{c}$, d EMT-related protein levels were measured by western blotting after DNER overexpression in BC cells. Right: quantitative analysis of the optical density ratio of E-cadherin, N-cadherin, Vimentin, and Snail compared with $\beta$-actin are shown. $\mathbf{e}, \mathbf{f}$ DNER was overexpressed in DNER knockdown cells, and then western blotting detected the expression of EMT-related proteins. The values are the mean \pm SD from three independent experiments. ${ }^{*} p<0.05,{ }^{* *} p<0.01,{ }^{* * *} p<0.001$ vs the corresponding group.

DNER activates the $W n t / \beta$-catenin signalling pathway and is positively correlated with $\beta$-catenin

Previous reports have shown that the $\mathrm{Wnt} / \beta$-catenin signalling pathway plays a crucial role in cancer cell metastasis and $\mathrm{EMT}^{20,21}$. Therefore, we examined whether DNER mediates the canonical Wnt/ $\beta$-catenin signalling pathway. As shown in Fig. 4a, b, compared with control cells, in DNER knockdown cells, the protein levels of Notch1, p-GSK3 $\beta$ and $\beta$-catenin were increased, and those of GSK3 $\beta$ were unchanged. Conversely, DNER overexpression dramatically shown the opposite effect. Next, we investigate whether there is a relationship between Notch signal and $\beta$-catenin in the case of DNER overexpression. In DNER-overexpressing cells, we knocked down Notch1 and found that $\beta$-catenin expression was decreased compared with DNER overexpression alone (Supplementary Fig. 2B). Notch1 functioned as an important role in the Wnt/ $\beta$-catenin pathway, and the activation of Notch 1 was positively related to the nuclear translocation of $\beta$-catenin ${ }^{22}$. The accumulation of $\beta$-catenin in the nucleus plays an important role in the malignant progression of tumours. We assessed the effect of DNER knockdown on nuclear $\beta$-catenin accumulation by western blotting and observed that upon the knockdown of DNER, the levels of nuclear $\beta$-catenin and Snail were reduced in $\mathrm{BC}$ cell lines (Fig. 4c and Supplementary Fig. 2C). The nuclear location of $\beta$-catenin detected by immunofluorescence showed the same results as those 


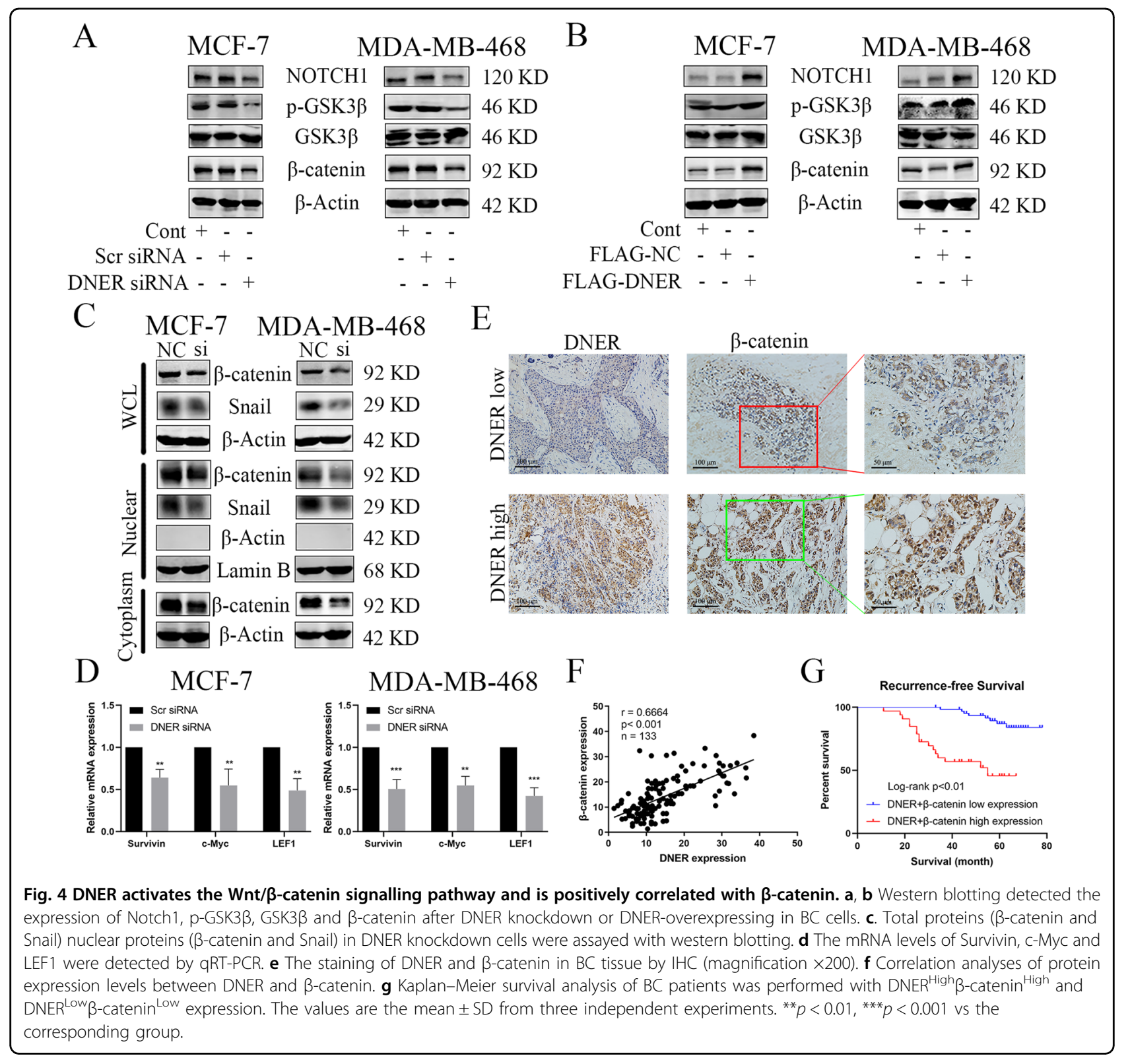

determined by western blotting (Supplementary Fig. 2D). To further confirm the decrease in nuclear $\beta$-catenin accumulation following DNER knockdown, we examined the expression levels of $\beta$-catenin downstream target genes in BC cells by PCR. Consistent with the western blotting results, the mRNA expression levels of Survivin, c-Myc and LEF1 were significantly downregulated upon DNER knockdown (Fig. 4d). These data indicated that DNER knockdown can inhibit nuclear translocation and transcriptional activity of $\beta$-catenin, thereby controlling the $\mathrm{Wnt} / \beta$-catenin signalling pathway.

To verify the relationship between DNER and $\beta$-catenin, we measured the protein expression levels of DNER and $\beta$-catenin in BC tissues. IHC showed that $\beta$-catenin was highly expressed when DNER was overexpressed, while catenin levels were low when DNER was knocked down (Fig. 4e). Interestingly, correlation analyses showed that $\beta$-catenin expression was positively correlated with the expression of DNER (Fig. 4f). We also found a strong positive correlation between DNER expression and nuclear $\beta$-catenin expression (Supplementary Fig. 2E). Furthermore, immunofluorescence analysis showed that DNER overexpression promoted more nuclear accumulation of $\beta$-catenin in BC cells (Supplementary Fig. 2F). Finally, Kaplan-Meier analysis showed that the prognosis of $\mathrm{BC}$ patients with high levels of DNER and $\beta$-catenin was worse than the prognosis of $\mathrm{BC}$ patients with low levels of both DNER and $\beta$-catenin (Fig. 4g). In addition, 
Table 3 Clinicopathological associations of both DNER and $\beta$-catenin expression in breast cancer.

\begin{tabular}{|c|c|c|c|}
\hline Variables & $\begin{array}{l}\text { Low } \\
N=70\end{array}$ & $\begin{array}{l}\text { High } \\
N=36\end{array}$ & $P$ value ${ }^{*}$ \\
\hline Age at diagnosis, years & & & 0.945 \\
\hline$\leq 50$ & $19(27.1)$ & $10(27.8)$ & \\
\hline$>50$ & $51(72.9)$ & $26(72.2)$ & \\
\hline Grade & & & 0.038 \\
\hline Well & $15(21.4)$ & $2(5.6)$ & \\
\hline Moderately & $19(27.2)$ & $7(19.4)$ & \\
\hline Poorly & $36(51.4)$ & $27(75.0)$ & \\
\hline Tumour size (cm) & & & 0.004 \\
\hline$\leq 2$ & $38(54.3)$ & $9(25.0)$ & \\
\hline$>2$ & $32(45.7)$ & $27(75.0)$ & \\
\hline Lymph node metastasis & & & 0.415 \\
\hline Negative & 27 (38.6) & $11(30.6)$ & \\
\hline Positive & $43(61.4)$ & $25(69.4)$ & \\
\hline Vascular invasion & & & 0.113 \\
\hline Negative & $58(82.9)$ & $25(69.4)$ & \\
\hline Positive & $12(27.1)$ & $11(30.6)$ & \\
\hline ER & & & 0.665 \\
\hline Negative & $58(82.9)$ & $31(86.1)$ & \\
\hline Positive & $12(27.1)$ & $5(13.9)$ & \\
\hline$P R$ & & & 0.003 \\
\hline Negative & $40(57.1)$ & $31(86.1)$ & \\
\hline Positive & $30(42.9)$ & $5(13.9)$ & \\
\hline HER2 & & & 0.057 \\
\hline Negative & $46(65.7)$ & $30(83.3)$ & \\
\hline Positive & $24(34.3)$ & $6(16.7)$ & \\
\hline Ki67 & & & 0.183 \\
\hline$<14 \%$ & $55(78.6)$ & $24(66.7)$ & \\
\hline$\geq 14 \%$ & $15(21.4)$ & $12(33.3)$ & \\
\hline Recurrence & & & $<0.01$ \\
\hline No & $62(88.6)$ & $20(55.6)$ & \\
\hline Yes & $8(11.4)$ & $16(44.4)$ & \\
\hline
\end{tabular}

${ }^{*} P$ values calculated by log-rank testing; bold if statistically significant, $P<0.05$. $E R$ oestrogen receptor, $P R$ progesterone receptor, HER2 human epithelial growth factor receptor-2.

we continued to show the correlation between the highlevel expression of both DNER and $\beta$-catenin and BC patient clinicopathologic features, as shown in Table 3. These data suggest a strong correlation between the expression of DNER with that of $\beta$-catenin and high levels of $D N E R / \beta$-catenin with poor prognosis in $B C$.
The Wnt/ $\beta$-catenin signalling pathway is involved in DNERinduced EMT and pro-metastatic phenotypes

To determine whether the Wnt//-catenin pathway functions in DNER-induced EMT, we assessed whether CHIR 99021, a specific Wnt/ $\beta$-catenin pathway activator $^{23}$, and XAV-939, a Wnt/ $\beta$-catenin pathway inhibitor $^{24}$ could reverse the effect of DNER overexpression and DNER knockdown in BC cells. $\beta$-Catenin levels in the two $\mathrm{BC}$ cell lines were significantly elevated after CHIR 99021 treatment and markedly suppressed after XAV-939 treatment (Fig. 5a, b). Compared with DNER knockdown alone, levels of the EMT-related proteins were dramatically exhibited the opposite effect after of the treatment of DNER knockdown cells with CHIR 99021 (Fig. 5a). The treatment of DNER-overexpressing cells with XAV-939 clearly show similar results (Fig. 5b). These findings indicated that CHIR 99021 partly rescued the inhibitory effect of DNER knockdown on EMT progression and that XAV-939 suppressed the activation of EMT induced by DNER overexpression. To investigate the role of the Wnt/ $\beta$-catenin pathway in DNER-mediated cell proliferation, migration and invasion, we performed rescue experiments by activating or inhibiting $\beta$-catenin in DNER knockdown or DNER-overexpressing cells, respectively. Consistent with the effects of Wnt/ $\mathrm{W}$-catenin pathway activation and inhibition on EMT, in the presence of CHIR 99021, the proliferation, migration and invasion of DNER knockdown cells were clearly elevated (Fig. 5c, e, f). Similarly, inhibition of $\beta$-catenin by XAV-939 in DNERoverexpressing cells distinctly decreased metastatic ability, as shown by changes in cell growth, migration and invasion (Fig. 5d, g, h). Altogether, these data suggested that $\beta$-catenin is indispensable for DNER-induced BC cell EMT and pro-metastatic phenotypes.

\section{DNER enhances the tumorigenic and metastatic ability of $B C$ cells in vivo}

To verify our results in vitro, we next examined the role of DNER in vivo. To that end, MDA-MB-468 cells in which DNER was stably knocked down and MCF-7 cells stably overexpressing DNER were successfully established to use to establish xenograft models in mice (Fig. 6a, b, f, g). After a period of time, the xenografts were removed, photographed and weighed. DNER knockdown significantly inhibited tumour size and weight compared with those in NC group (Fig. 6c, d). Consistent with the effect of DNER knockdown, xenografts from DNERoverexpressing group were larger and heavier than those from NC group. More importantly, XAV-939 reversed changes in the size and weight of xenografts (Fig. 6h, i). The DNER, $\beta$-catenin, c-Myc and Snail protein levels in xenograft tissue were measured to confirm the upregulation and downregulation by western blotting (Fig. 6e, j, Supplementary Fig. 3A). Moreover, IHC results found 


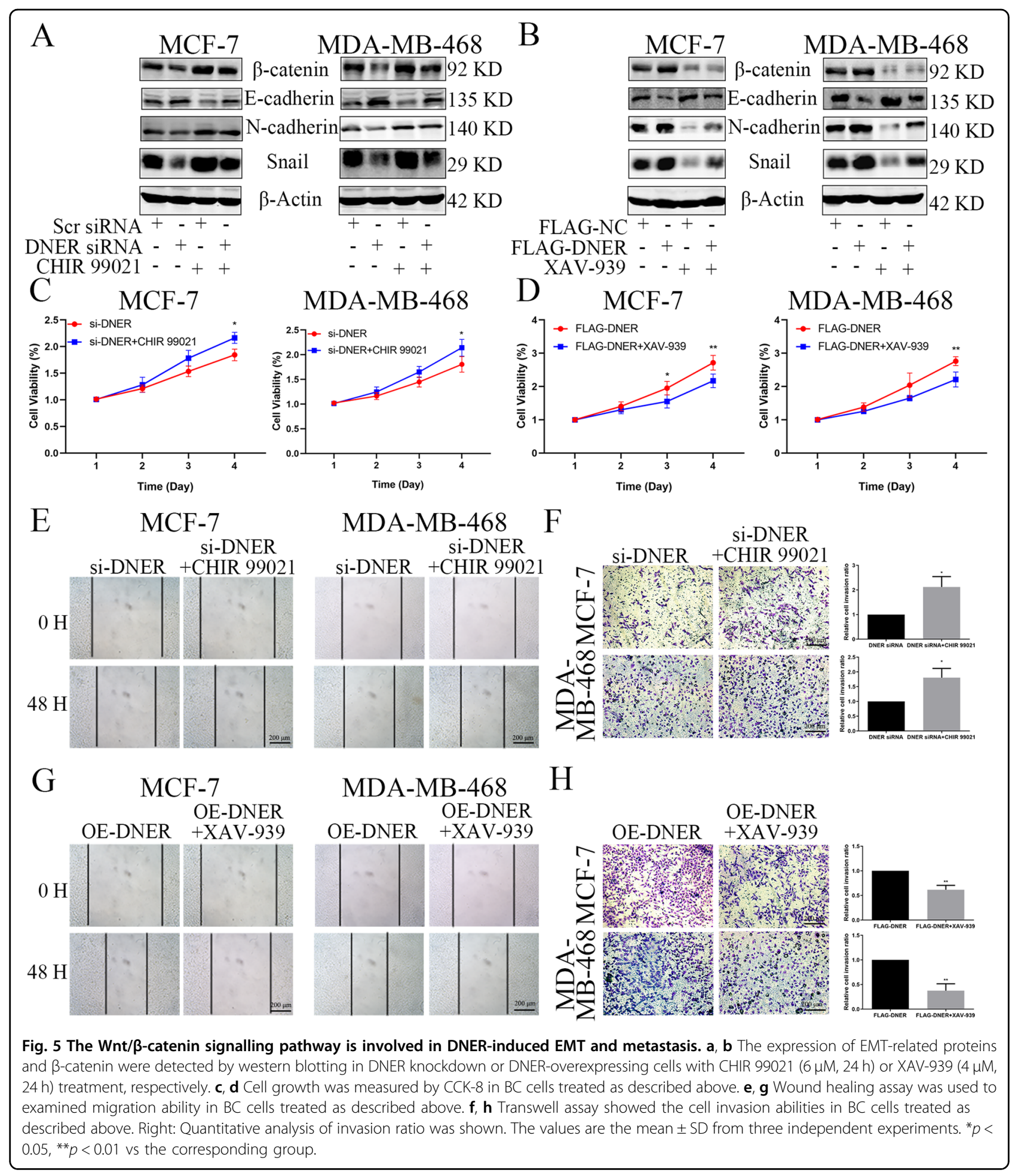

that DNER knockdown reduced nuclear location of $\beta$-catenin, while DNER overexpression promoted this nuclear translocation effect (Supplementary Fig. 3C). In addition, as shown in Supplementary Fig. 3A, C, the western blotting and IHC results showed that DNER impacted the tumour growth in vivo was related to the level of Ki67, which is consistent with the positive correlation between DNER expression and ki67 expression in BC patients of TCGA database (Supplementary Fig. 3B).

To explore the role of DNER in BC metastasis to lung, MDA-MB-231 cells with stably DNER knockdown was successfully established (Fig. 6k). As shown in Fig. 6l, the 


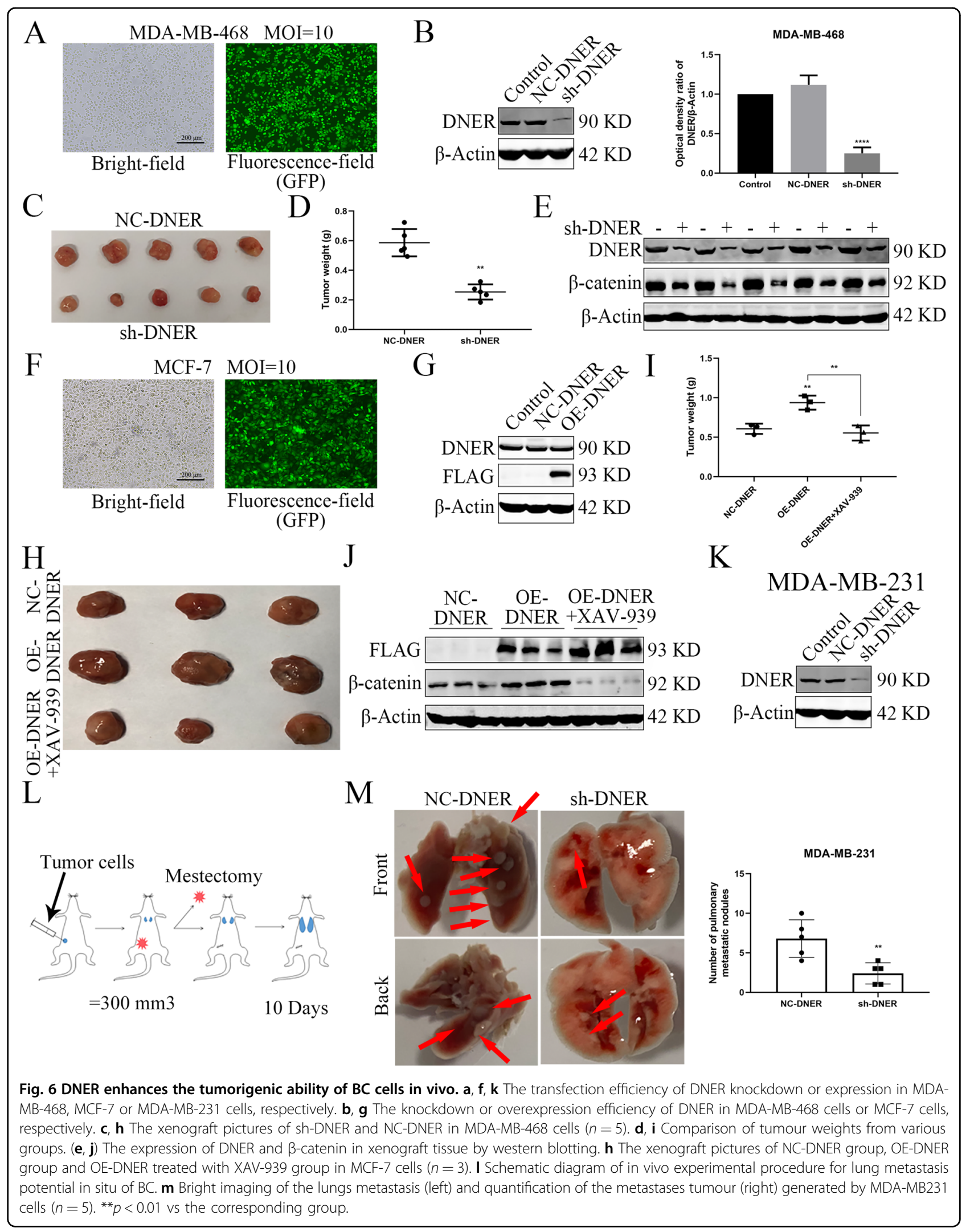




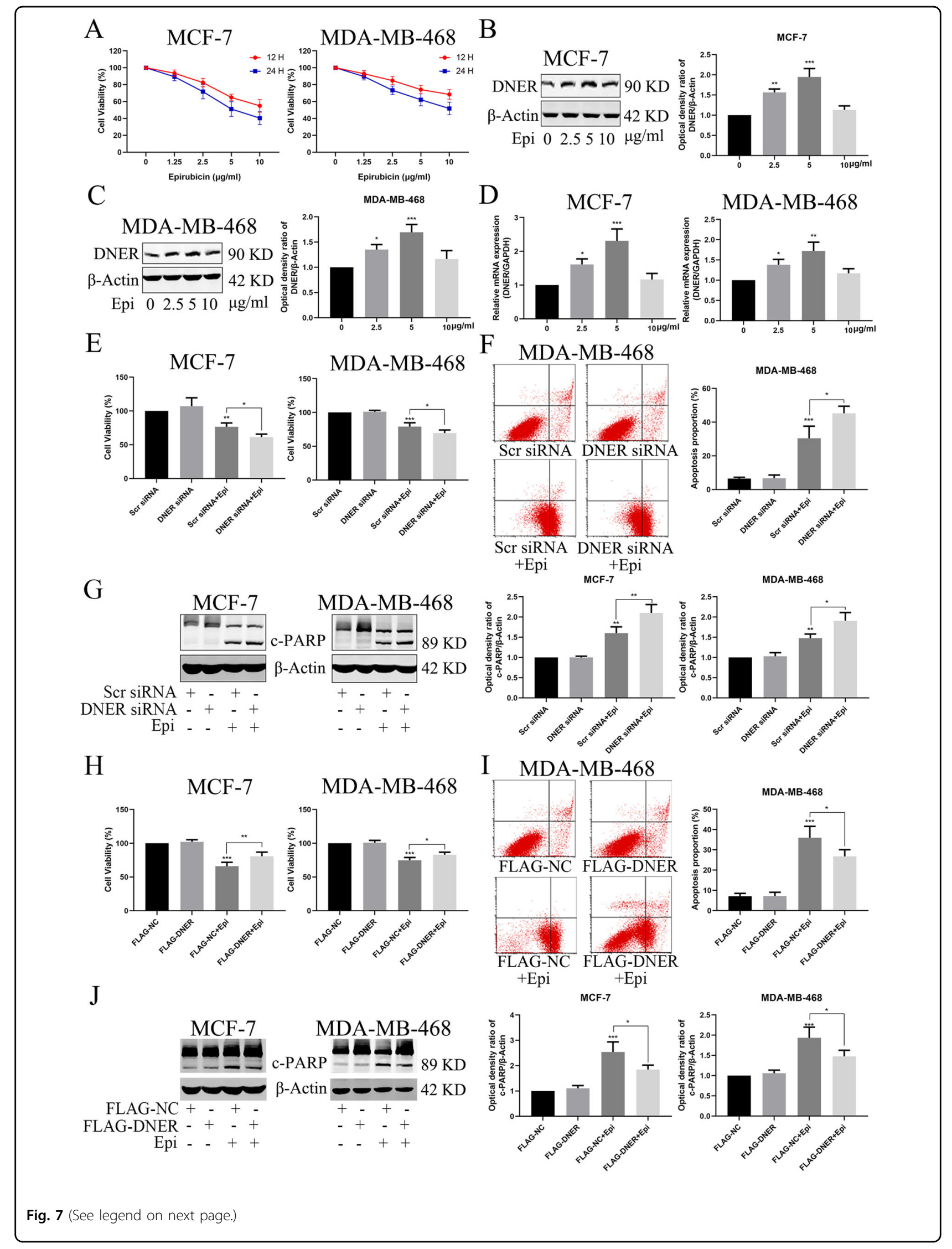


(see figure on previous page)

Fig. 7 DNER reduces the chemosensitivity of BC cells to epirubicin in vitro. a Cell proliferation was detected by CCK-8 after treated with different concentrations of epirubicin in two BC cell lines. b, $\mathbf{c}$ DNER was analyzed by western blotting in BC cells treated as described above. Right: quantitative analysis of the optical density ratio of DNER compared with $\beta$-actin are shown. $\mathbf{d}$ Expression of epirubicin-induced DNER was detected by PCR. e Cell viability was assessed by CCK-8 after DNER knockdown treated with epirubicin or not. $\mathbf{f}$ Analysis of apoptosis with FACS in MDA-MB468 cells treated as described in (e). Right: Quantitative analysis of apoptosis ratio. $\mathbf{g}$ The expression of PARP was detected by western blotting in BC cells treated as described above. Right: quantitative analysis of the optical density ratio of c-PARP compared with $\beta$-actin are shown. $\mathbf{h}$ Cell growth was measured by CCK-8 after DNER overexpression treated with epirubicin or not. $\mathbf{i}$ Analysis of apoptosis with FACS in MDA-MB-468 cells treated as described in (h). Right: Quantitative analysis of apoptosis ratio. $\mathbf{j}$ The expression of PARP was detected by western blotting in BC cells treated as described above. Right: quantitative analysis of the optical density ratio of c-PARP compared with $\beta$-actin are shown. The values are the mean \pm SD from three independent experiments. ${ }^{*} p<0.05,{ }^{* *} p<0.01,{ }^{* * *} p<0.001$ vs the corresponding group.

corresponding treated MDA-MB-231 cells were injected into the fourth mammary fat pad, and tumours were excised when they reached about $300 \mathrm{~mm}^{3}$. Lung metastasis was observed in each group after 10 days. Bright-field picture demonstrated that more lung metastasis was found in the NC-DNER group compared with the shDNER group (Fig. 6m). Similar trends were observable in H\&E staining analysis (Supplementary Fig. 3E). Moreover, IHC results of xenografts showed that DNER knockdown observably upregulated E-cadherin expression and downregulated N-cadherin expression. DNER overexpression had the opposite effect, whereas XAV-939 reversed the expression levels of EMT markers (Supplementary Fig. 3C, D), indicated that DNER promoted BC metastasis in vivo. These results illuminate that DNER functions as an oncogene in $\mathrm{BC}$.

\section{DNER reduces the chemosensitivity of BC cells to epirubicin in vitro}

Previous studies have reported that EMT is involved in the chemosensitivity of tumour cells. Our results suggested that DNER promotes EMT in BC cells. Therefore, we examined the relationship between DNER and chemosensitivity to epirubicin. As shown in Fig. 7a, epirubicin inhibited the growth of the two $\mathrm{BC}$ cell lines in a concentration- and time-dependent manner. Meanwhile, DNER was elevated at both the protein and mRNA levels after $\mathrm{BC}$ cells were treated with different concentrations of epirubicin $(1.25-5 \mu \mathrm{g} / \mathrm{ml})$ for $12 \mathrm{~h}$, but returned to the control level at $10 \mu \mathrm{g} / \mathrm{ml}$ (Fig. 7b-d). Next, we investigated the role of DNER in epirubicin-induced apoptosis. The CCK- 8 assay showed that the combination of DNER knockdown and epirubicin treatment had a significant inhibitory effect on cell proliferation compared to that with epirubicin treatment alone (Fig. 7e). Furthermore, DNER knockdown with epirubicin treatment dramatically augmented the apoptosis rate compared with that in the epirubicin group of MDA-MB-468 cells, as determined by fluorescence-activated cell sorting (FACS) (Fig. 7f). The levels of apoptosis-related proteins, such as PARP, detected by western blotting were the same as those determined by FACS (Fig. 7g), indicating the protective role of DNER in epirubicin-induced apoptosis. To further confirm the protective role of DNER against epirubicininduced apoptosis, we measured cell viability and apoptosis after overexpressing DNER. The CCK- 8 assay showed that DNER overexpression could partially rescue the inhibition of cell proliferation induced by epirubicin (Fig. 7h). Unlike the effects of DNER knockdown determined by FACS and western blotting, DNER overexpression significantly antagonized epirubicin-induced apoptosis in $\mathrm{BC}$ cells (Fig. 7i, j). Taken together, these results demonstrate that DNER protects $\mathrm{BC}$ cells from epirubicin-induced apoptosis.

\section{Regulation of the Wnt/ $\beta$-catenin pathway by DNER is involved in epirubicin-induced apoptosis}

We have previously shown that DNER can regulate the Wnt $/ \beta$-catenin signalling pathway. To determine whether $\beta$-catenin is involved in the epirubicin-induced apoptosis of $\mathrm{BC}$ cells, two $\mathrm{BC}$ cell lines were treated with different concentrations of epirubicin. As shown in Fig. 8a, the protein levels of $\beta$-catenin in $B C$ cells were increased in an epirubicin concentration-dependent manner. Furthermore, upregulation of $\beta$-catenin induced by epirubicin occurred at the transcriptional level (Fig. 8b). More importantly, $\beta$-catenin was transferred into the nucleus after epirubicin treatment (Fig. 8c, d). We next examined cell growth and apoptosis in DNER-overexpressing cells in the absence and presence of XAV-939. A CCK-8 assay showed that the treatment of DNER-overexpressing cells with XAV-939 augmented the epirubicin-induced inhibition of cell proliferation compared with that when DNER was overexpressed alone (Fig. 8e). In addition, FACS revealed that the rate of epirubicin-induced apoptosis in DNER-overexpressing MDA-MB-468 cells was significantly elevated after XAV-939 treatment (Fig. 8f). Furthermore, changes in the levels of apoptosis-related proteins indicated the same outcome as FACS (Fig. 8g). These results showed that $\beta$-catenin amplified the rate of epirubicin-induced apoptosis, which was reversed by DNER; therefore, we conclude that DNER inhibits 


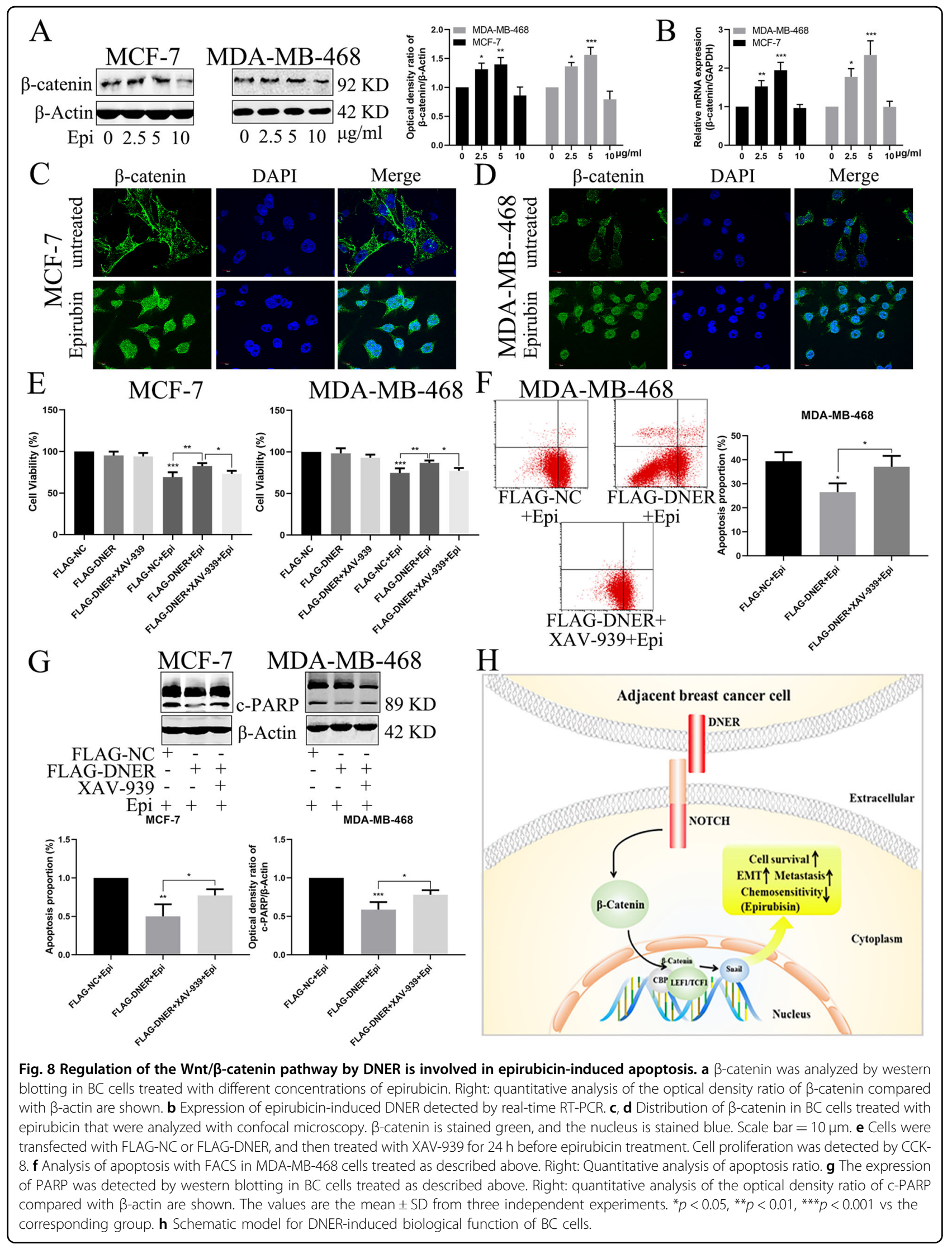


epirubicin-induced cell apoptosis via the Wnt/ $\beta$-catenin signalling pathway (Fig. 8h).

\section{Discussion}

In our study, we have provided comprehensive results on the role of DNER in regulating BC EMT and chemosensitivity. We found that the expression level of DNER in BC tissue, especially TNBC tissue, is obviously higher than that in adjacent tissue and that high DNER expression is associated with poor prognosis in $\mathrm{BC}$ and TNBC patients. Furthermore, DNER not only clearly enhanced cell viability, migration, invasion and EMT in vitro but also significantly augmented the tumorigenic and metastatic ability in vivo. In addition, we demonstrated that Wnt $/ \beta$-catenin is essential for DNER-mediated cell growth, migration, invasion and EMT and that patients with high levels of DNER and $\beta$-catenin exhibit worse survival. Finally, DNER protects BC cells from epirubicininduced apoptosis via the Wnt/ß-catenin pathway. Therefore, DNER functions as an oncogene in BC and may be a prognostic factor and therapeutic target for $\mathrm{BC}$.

DNER, atypical ligand of the Notch1 pathway, was initially found to be highly expressed in Purkinje neurons and plays a key role in cerebellar development ${ }^{25,26}$. Furthermore, the Notch pathway is involved in carcinogenesis and promotes the proliferation and malignant progression of various tumours ${ }^{27-29}$. Until now, the role of DNER in cancer has remained controversial, and the function of DNER may vary according to cell type. Several studies have shown that knockdown of DNER by siRNA or shRNA inhibits cancer cell proliferation, migration and invasion in vitro and reduces the size of some solid tumours in vivo ${ }^{16,17,30}$. However, in glioblastoma, the specific gene product induced by DNER-mediated histone deacetylase (HDAC) inhibition inhibits the growth of GBM-derived neurospheres, induces differentiation in vitro and in vivo and inhibits tumour xenograft growth ${ }^{14}$. Our results demonstrated that DNER remarkedly promoted the cell growth, migration and invasion of $\mathrm{BC}$ cell lines in vitro and augmented the tumorigenic and metastatic ability in vivo. These inconsistent findings suggest that the role of DNER is tissue- or cell-specific or that HDAC inhibitors inhibit the proliferation of glioblastoma by inhibiting the expression of DNER, thereby protecting the body. Furthermore, DNER could reduce the RFS in BC patients, especially TNBC patients, suggesting DNER as a prognostic indicator in $\mathrm{BC}$, especially TNBC.

A growing body of research suggests that the distant metastasis of tumours is caused by EMT of tumour cells, which promotes cancer cell metastasis ${ }^{10,31}$. In addition, DNER acts as a ligand for Notch1, activating the Notch signalling pathway ${ }^{11,15}$, and the knockdown of Notch1 expression can inhibit the migration and invasion of nasopharyngeal carcinoma cells by reversing $\mathrm{EMT}^{32}$. In our study, the knockdown of DNER significantly increased the expression of epithelial markers and inhibited the expression of interstitial markers, while DNER overexpression had the opposite effect. Furthermore, overexpression of DNER in DNER knockdown cells reversed the EMT phenotype. These results revealed that DNER promotes $\mathrm{BC}$ progression through regulating cell EMT.

The canonical Wnt/ $\beta$-catenin pathway plays a critical role in the apoptosis, proliferation and metastasis of cancer cells ${ }^{10,33}$. Our research demonstrated that DNER observably activates the $\mathrm{Wnt} / \beta$-catenin pathway to regulate the proliferation, migration, invasion and EMT of $\mathrm{BC}$ cells. This finding was verified by nuclear and cytoplasmic separation experiments and downstream target gene detection with qRT-PCR after DNER knockdown. Furthermore, CHIR 99021 and XAV-939 reversed change to cellular biological functions and the EMT phenotype after DNER knockdown and overexpression, respectively. In addition, we demonstrated a positive correlation between DNER and catenin. Furthermore, BC patients with combined high expression levels of DNER and $\beta$-catenin exhibited worse survival. Hence, Wnt $/ \beta$-catenin is not only regulated by DNER but also participates in the prognosis of $\mathrm{BC}$ patients together with DNER.

The effect of $\beta$-catenin and EMT on cell apoptosis has been reported ${ }^{34,35}$, but the role of DNER in epirubicininduced apoptosis has not been studied. DNER and $\beta$-catenin were expressed in an epirubicin concentrationdependent manner. Knockdown of DNER significantly increased the epirubicin-induced inhibition of cell proliferation and apoptosis, while overexpression of DNER had the opposite effect. More interestingly, the extent to which epirubicin inhibited proliferation and cell apoptosis in DNER-overexpressing cells was dramatically enhanced after XAV-939 treatment. These results indicated that DNER protects BC cells from epirubicin-induced growth inhibition and apoptosis via the $\mathrm{Wnt} / \beta$-catenin pathway.

In conclusion, we have demonstrated the crucial functional role of DNER in EMT and apoptosis. Our study revealed that DNER is highly expressed and associated with poor survival in BC patients, especially TNBC patients, as shown for the first time. In addition, DNER promotes BC cell invasion, EMT and the rate of apoptosis by regulating the $\mathrm{Wnt} / \beta$-catenin pathway. Therefore, although further research is needed, our study provides comprehensive evidence demonstrating the value of DNER in EMT and apoptosis and suggests DNER as a worthwhile therapeutic target for BC.

\footnotetext{
Acknowledgements

We would like to thank the participating patients for the source of BC tissue specimens. This work was partially supported by a National Natural Science
} Foundation of China (NSFC) grant (grant no. 81471781) and a National Major 
Scientific Instruments and Equipment Development Projects grant (grant no. 2012YQ160203) to S.S., an NSFC grant to C.W. (grant no. 81870550), an NSFC grant (grant no:: 81903166), the Hubei Province Health and Family Planning Scientific Research Project (RMYD2018M78) and a grant from the Scientific Research Project of the Hubei Provincial Health Commission (WJ2019Q044) to S.S.

\section{Author details}

${ }^{1}$ Department of Breast and Thyroid Surgery, Renmin Hospital of Wuhan University, Wuhan, Hubei, China. ${ }^{2}$ Department of Pathophysiology, Wuhan University School of Basic Medical Sciences, Wuhan, Hubei, China. ${ }^{3}$ Department of Clinical Laboratory, Renmin Hospital of Wuhan University, Wuhan, Hubei, China

\section{Conflict of interest}

The authors declare that they have no conflict of interest.

\section{Publisher's note}

Springer Nature remains neutral with regard to jurisdictional claims in published maps and institutional affiliations.

Supplementary Information accompanies this paper at (https://doi.org/ 10.1038/s41419-020-02903-1).

Received: 12 October 2019 Revised: 2 August 2020 Accepted: 3 August 2020

Published online: 18 August 2020

\section{References}

1. Bray, F. et al. Global cancer statistics 2018: GLOBOCAN estimates of incidence and mortality worldwide for 36 cancers in 185 countries. CA Cancer J. Clin. 68, 394-424 (2018).

2. Sauer, A. G., Siegel, R. L., Jemal, A. \& Fedewa, S. A. Updated review of prevalence of major risk factors and use of screening tests for cancer in the United States. Cancer Epidemiol. Biomark. Prev. 26, 1192-1208 (2017).

3. Gruver, A. M., Portier, B. P. \& Tubbs, R. R. Molecular pathology of breast cancer: the journey from traditional practice toward embracing the complexity of a molecular classification. Arch. Pathol. Lab. Med. 135, 544-557 (2011).

4. Nieto, M. A., Huang, R. Y., Jackson, R. A. \& Thiery, J. P. EMT: 2016. Cell 166, 21-45 (2016).

5. Gupta, S. \& Maitra, A. EMT: matter of life or death? Cell 164, 840-842 (2016).

6. David, C. J. et al. TGF-beta tumor suppression through a lethal EMT. Cell 164 1015-1030 (2016).

7. Yeung, K. T. \& Yang, J. Epithelial-mesenchymal transition in tumor metastasis. Mol. Oncol. 11, 28-39 (2017).

8. Nowrin, K., Sohal, S. S., Peterson, G., Patel, R. \& Walters, E. H. Epithelialmesenchymal transition as a fundamental underlying pathogenic process in COPD airways: fibrosis, remodeling and cancer. Expert Rev. Respir. Med. 8 547-559 (2014).

9. $\mathrm{Hu}, \mathrm{J}$. L. et al. CAFs secreted exosomes promote metastasis and chemotherapy resistance by enhancing cell stemness and epithelial-mesenchymal transition in colorectal cancer. Mol. Cancer 18, 91 (2019).

10. Zhou, P. et al. NMIIA promotes tumor growth and metastasis by activating the Wnt/beta-catenin signaling pathway and EMT in pancreatic cancer. Oncogene 38, 5500-5515 (2019).

11. Eiraku, M. et al. DNER acts as a neuron-specific Notch ligand during Bergmann glial development. Nat. Neurosci. 8, 873-880 (2005).

12. Park, J. R. et al. DNER modulates adipogenesis of human adipose tissuederived mesenchymal stem cells via regulation of cell proliferation. Cell Prolif. 43, 19-28 (2010).

13. Hartman, B. H., Nelson, B. R., Reh, T. A. \& Bermingham-McDonogh, O. Delta/ notch-like EGF-related receptor (DNER) is expressed in hair cells and neurons in the developing and adult mouse inner ear. J. Assoc. Res. Otolaryngol. 11, 187-201 (2010).

14. Sun, P. et al. DNER, an epigenetically modulated gene, regulates glioblastomaderived neurosphere cell differentiation and tumor propagation. Stem Cells 27, 1473-1486 (2009).

15. D'Souza, B., Meloty-Kapella, L. \& Weinmaster, G. Canonical and non-canonical Notch ligands. Curr. Top. Dev. Biol. 92, 73-129 (2010).

16. Wang, L. et al. Delta/notch-like epidermal growth factor-related receptor (DNER) orchestrates stemness and cancer progression in prostate cancer. Am. J. Transl. Res. 9, 5031-5039 (2017).

17. Wang, L. et al. Delta/notch-like epidermal growth factor-related receptor promotes stemness to facilitate breast cancer progression. Cell. Signal. 63 , 109389 (2019).

18. Zheng, $\mathrm{H}$. et al. Quantum dot-based immunofluorescent imaging and quantitative detection of TOP2A and prognostic value in triple-negative breast cancer. Int. J. Nanomed. 11, 5519-5529 (2016).

19. Wang, Z. et al. Escin-induced DNA damage promotes escin-induced apoptosis in human colorectal cancer cells via p62 regulation of the ATM/gammaH2AX pathway. Acta Pharm. Sin. 39, 1645-1660 (2018).

20. Wu, J. et al. TET1-mediated DNA hydroxymethylation activates inhibitors of the Wnt/beta-catenin signaling pathway to suppress EMT in pancreatic tumor cells. J. Exp. Clin. Cancer Res. 38, 348 (2019).

21. Colella, B., Faienza, F. \& Di Bartolomeo, S. EMT regulation by autophagy: a new perspective in glioblastoma biology. Cancers 11, https:/doi.org/10.3390/ cancers 11030312 (2019).

22. Ishiguro, $\mathrm{H}$. et al. NOTCH1 activates the $\mathrm{Wnt} /$ beta-catenin signaling pathway in colon cancer. Oncotarget 8, 60378-60389 (2017).

23. Liu, C. C. et al. FERMT1 mediates epithelial-mesenchymal transition to promote colon cancer metastasis via modulation of beta-catenin transcriptional activity. Oncogene 36, 1779-1792 (2017).

24. Li, H. et al. Nucleolar and spindle associated protein 1 promotes metastasis of cervical carcinoma cells by activating Wnt/beta-catenin signaling. J. Exp. Clin. Cancer Res. 38, 33 (2019).

25. Eiraku, M., Hirata, Y., Takeshima, H., Hirano, T. \& Kengaku, M. Delta/notch-like epidermal growth factor (EGF)-related receptor, a novel EGF-like repeat-containing protein targeted to dendrites of developing and adult central nervous system neurons. J. Biol. Chem. 277, 25400-25407 (2002).

26. Tohgo, A. et al. Impaired cerebellar functions in mutant mice lacking DNER. Mol. Cell Neurosci. 31, 326-333 (2006)

27. Lu, H. Y. et al. Novel ADAM-17 inhibitor ZLDI-8 inhibits the proliferation and metastasis of chemo-resistant non-small-cell lung cancer by reversing Notch and epithelial mesenchymal transition in vitro and in vivo. Pharmacol. Res. 104406, https://doi.org/10.1016/j.phrs.2019.104406 (2019).

28. Liubomirski, Y. et al. Notch-mediated tumor-stroma-inflammation networks promote invasive properties and CXCL8 expression in triple-negative breast cancer. Front. Immunol. 10, 804 (2019).

29. Ye, Y. C. et al. NOTCH signaling via WNT regulates the proliferation of alternative, CCR2-independent tumor-associated macrophages in hepatocellular carcinoma. Cancer Res. 79, 4160-4172 (2019).

30. Liang, Y., Luo, H., Zhang, H., Dong, Y. \& Bao, Y. Oncogene delta/Notch-like EGFrelated receptor promotes cell proliferation, invasion, and migration in hepatocellular carcinoma and predicts a poor prognosis. Cancer Biother. Radiopharm. 33, 380-386 (2018).

31. Zhao, Y. R. et al. HEG1 indicates poor prognosis and promotes hepatocellular carcinoma invasion, metastasis, and EMT by activating Wnt/beta-catenin signaling. Clin. Sci. 133, 1645-1662 (2019).

32. Guo, H. et al. Knockdown of Notch1 inhibits nasopharyngeal carcinoma cell growth and metastasis via downregulation of CCL2, CXCL16, and UPA. Mol Carcinog 58, 1886-1896 (2019).

33. Zou, A. et al. SHCBP1 promotes cisplatin induced apoptosis resistance, migration and invasion through activating Wnt pathway. Life Sci, 116798, https://doi.org/10.1016/j.lfs.2019.116798 (2019).

34. Wang, P. et al. Jatrorrhizine inhibits colorectal carcinoma proliferation and metastasis through Wnt/beta-catenin signaling pathway and epithelialmesenchymal transition. Drug Des. Devel Ther. 13, 2235-2247 (2019).

35. Singh, A. \& Settleman, J. EMT, cancer stem cells and drug resistance: an emerging axis of evil in the war on cancer. Oncogene 29, 4741-4751 (2010). 